\title{
Study on Transferring and Diffusing of the Radioactive Nuclidesafter Coastal Nuclear Power Plant Accidentin Coastal Seawater
}

\author{
WANG Shao-wei \\ Nuclear and Radiation Safety Center of MEP NSC \\ Beijing, China \\ wangshaowei@chinansc.cn
}

\author{
HOU Jie \\ Nuclear and Radiation Safety Center of MEP NSC \\ Beijing, China
}

\author{
CHEN Hai-ying \\ Nuclear and Radiation Safety Center of \\ MEP NSC \\ Beijing, China
}

\author{
QIAO Qing-dang \\ Nuclear and Radiation Safety Center of \\ MEP NSC \\ Beijing, China
}

\author{
YUE Hui-guo \\ Nuclear and Radiation Safety Center of \\ MEP NSC \\ Beijing, China
}

\begin{abstract}
A large amount of radioactive substances have been discharged into the sea during the Fukushima nuclear accident, which did tremendous harm to the marine ecological environment. The progress in study of relocation diffusion and transformation of radionuclide in water from coastal nuclear power plant accident are reviewed in this paper. The factors influencing the diffusion and transformationof radionuclide are discussed and analyzed from discharge source item, characteristic of coastal environment, simulation of radionuclide relocation diffusion. Based on the existing studies and researches, the characteristic of coastal environment and the reactor type of a coastal nuclear power plant in China, a computer systemsimulating the transferring and diffusing of the radioactive nuclides after accident in coastal seawater was designed and developed. The main models of system were introduced, including fluid dynamics model, transportation of sediments model and nuclide transportation model.
\end{abstract}

Keywords-coastal nuclear power; accident condition; transferring of the radioactive nuclides; diffusing of the radioactive nuclides

\section{INTRODUCTION}

Potential radioactive material release may exert an acute impact on the environment [1,2]. Since the March 11st, 2011, It has been estimated that a large amount of radioactive waste water be dumped into the sea. Almost $1.8 \times 1016 \mathrm{~Bq}$ I131 equivalent of radioactivity are flow into the sea[3]. In case of huge amount of radioactivity released into water during the accidents, it is necessary to make consequence evaluation for the radioactive impact to water.

\section{RESEARCH DEVELOPMENTS}

There are relative small number of researches on the consequence evaluation to radioactive fluid. Among these, most focus on the radioactive release of nuclear power plant in normal operation. However, during severe nuclear accident when large amount of radioactivity released into the sea, it is hard to predict the distribution and the transportation of the radioactive material in the ocean in recent days. IAEA provides a general model for evaluating the coastal shore release under control. The diffusion equation assumes that the deepness and velocity of water is a constant in the model [4].

As it is to the emergency radioactive release to the water, there is different evaluation model. In 1957, although Windscale nuclear power plant accident is closed to the sea, there is no evident impact on the marine lives. After Chernobyl nuclear accident in 1986, the major impact is the radioactive deposition from the air. In 2002, RODOS (Real-time On-line Decision Support ) which developed by European Commission has added THREETOX 3-D hydraulic model which includes sediment transportation and radionuclide transportation. In the paper [6, 7], Margvelashvily has rebuilt the dispersion of Cs137 and Sr-90 diffusion in the estuaries and shelf seas.After FUKUSHIMA nuclear accidents, researches of Daisuke Tsumune simulate the distribution of Cs-137 in the sea by Regional Ocean Modeling system[8].

\section{FACTORS OF INFLUENCING THE DIFFUSION AND} TRANSFORMATION OF RADIONUCLIDE IN COASTAL SEAWATER

To establish the method of evaluation for the radioactive material to the coastal water, it is necessary to make analysis to the release source term, water character and transportation of isotopes.

\section{A. Source Terms}

During the nuclear power plant accident, when fuel cracked or core melted, the released radioactive material may come from the primary loop. It is also happened that the radioactive material released from the primary to the secondary because of the steam generator $U$ tuberupture. 
What is worse, when the spent fuel pool been damaged, there is risk that the residual heat will cause the assembly damage and the radioactivity may flow to the sea accompanied with cooling water. This is happened in the Fukushima nuclear accident. Different types of reactors, operation periods or inventory will by no means lead to different amount of fission isotopes in accidents.

When the nuclear power plant is on the normal operation, the isotopes can be monitored online routinely. Most of time, it follows the requirements. However, when it comes to the accident, it is hardly to get the specific source term to environment, the evaluation to radioactive source should base on the assumed models and emergency monitoring. Especially to sea water release, it may too urgent to get the enough monitoring data. Meanwhile, compared to the direct release to the sea, the radioactive material can be dispersed and settled down of the surface of water. Besides, one may consider the transportation from the earth to underground water, then flow to the sea.

The radioactive source term relies on both release paths and transportation in the fluid. There are multi-barriers to stop fission products released directly into environment, includes fuel assembly, primary pressure boundary and containments. Although these barriers, there is a risk that radioactive fluid can released from some other paths like containment bypass or steam generator tube rupture. When the radioactivity release into the sea, it is need to focus on the dispersion in the water body. For instance, precipitation washout, percolationand seepage, airborne deposition will by no means influence the evaluation results.

\section{B. Environmental Characters of Sea and Discharge Outlet}

Use either SI (MKS) or CGS as primary units. (SI units are encouraged.) English units may be used as secondary units (in parentheses). An exception would be the use of English units as identifiers in trade, such as "3.5-inch disk drive". Most of the nuclear power plant located near seashore of China. There is a potential risk that a large amount of radioactivity may release into the water in the accident. Although there are differences between the different sites, there are generally sea environmental character in common, includes sea function division, fishery, tidal parameters, hydraulic parameters, meteorological elements and so on. Among these, the main hydraulic parameters include water temperature, salinity, convection and diffusioncharacteristic (flow velocity, flow direction), tidal range, heat transfer coefficient, and roughness coefficient etc. The meteorological parameters includes temperature, air pressure, moist and wind speed etc.

The characteristics of discharge outlet include outlet type, elevation and size, which are influenced by sea topography, ocean current, tidal range, water temperature, thermal power of plant and so forth.According to the characteristics of coastal environment and the reactor type, the discharge outlets are significant different.

\section{Analysis to Radioactivity Transportation and Simulation}

Transportation of the radioactivity in the water is a complicated process, and it can be affected by a lot of factors.
The simulation of this process is based on numerical analysis. The calculation relate to the parameters like meteorological condition, deepness of the water and boundary between the water and air. The simulation process should include the model development, parameterization, diagnosis and verification.

\section{The Proposed System Simulating The \\ TrANSFERRING AND DifFUSING OF THE RADIOACTIVE NUCLIDES}

The proposed evaluation system should include model of fluid dynamics, sediment transportation, radioactive transportation, numerical calculation and consequence evaluation. The first three models will be introduced in details.

\section{A. Fluid Dynamics Model}

Dynamics equations are based on 3D non-condensed andvariable density turbulent boundary layer equations, which use Boussinesq assumption to correct the buoyancy lift item error caused by density difference. After the curve orthogonal coordinate transformation in the horizontal and sigma coordinate transformation in the vertical, the converted control equation is:

Momentum equation:

$$
\begin{gathered}
\frac{\partial(m H u)}{\partial t}+\frac{\partial\left(m_{y} H u u\right)}{\partial x}+\frac{\partial\left(m_{x} H v u\right)}{\partial y}+\frac{\partial(m w u)}{\partial z}-\left(m f+v \frac{\partial m_{y}}{\partial x}-u \frac{\partial m_{x}}{\partial y}\right) H v \\
=-m_{y} H \frac{\partial(g \zeta+p)}{\partial x}-m_{y}\left(\frac{\partial h}{\partial x}-z \frac{\partial H}{\partial x}\right) \frac{\partial p}{\partial z}+\frac{\partial}{\partial z}\left(m \frac{1}{H} A \frac{\partial u}{\partial z}\right)+Q_{u} \\
\frac{\partial(m H v)}{\partial t}+\frac{\partial\left(m_{y} H u v\right)}{\partial x}+\frac{\partial\left(m_{x} H v\right)}{\partial y}+\frac{\partial(m w v)}{\partial z}+\left(m f+v \frac{\partial m_{y}}{\partial x}-u \frac{\partial m_{x}}{\partial y}\right) H u \\
=-m_{x} H \frac{\partial(g \zeta+p)}{\partial y}-m_{x}\left(\frac{\partial h}{\partial y}-z \frac{\partial H}{\partial y}\right) \frac{\partial p}{\partial z}+\frac{\partial}{\partial z}\left(m \frac{1}{H} A \frac{\partial v}{\partial z}\right)+Q_{v} \\
\frac{\partial p}{\partial z}=-g H \frac{\rho-\rho_{0}}{\rho_{0}}=-g H b
\end{gathered}
$$

Continuity equation:

$$
\begin{gathered}
\frac{\partial(m \zeta)}{\partial t}+\frac{\partial\left(m_{y} H u\right)}{\partial x}+\frac{\partial\left(m_{x} H v\right)}{\partial y}+\frac{\partial(m w)}{\partial z}=0 \\
\frac{\partial(m \zeta)}{\partial t}+\frac{\partial\left(m_{y} H \int_{0}^{1} u d z\right)}{\partial x}+\frac{\partial\left(m_{x} H \int_{0}^{1} v d z\right)}{\partial y}=0 \\
\rho=\rho(p, S, T)
\end{gathered}
$$

Mass transportation equation:

$$
\begin{aligned}
& \frac{\partial(m H S)}{\partial t}+\frac{\partial\left(m_{y} H u S\right)}{\partial x}+\frac{\partial\left(m_{x} H v S\right)}{\partial y}+\frac{\partial(m w S)}{\partial z}=\frac{\partial}{\partial z}\left(m \frac{1}{H} A_{b} \frac{\partial S}{\partial z}\right)+Q_{S}(7) \\
& \frac{\partial(m H T)}{\partial t}+\frac{\partial\left(m_{y} H u T\right)}{\partial x}+\frac{\partial\left(m_{x} H v T\right)}{\partial y}+\frac{\partial(m w T)}{\partial z}=\frac{\partial}{\partial z}\left(m \frac{1}{H} A_{\frac{1}{}} \frac{\partial T}{\partial z}\right)+Q_{T}(8)
\end{aligned}
$$


In the above equations, $u 、 v 、 \mathrm{~W}$ are respectively horizontal velocity component of $x, y, \mathrm{z}$ direction in curve orthogonal coordinate; $m_{x}$ and $m_{y}$ are horizontal coordinate transformation scale factors; $A_{\mathrm{v}}$ is the coefficient of vertical turbulence viscosity; ${ }^{A}$ is the coefficient of vertical diffusion viscosity; $\mathrm{f}$ is Coriolis coefficient; $P$ is pressure; $\rho_{\text {is mixture density; }} \rho_{\mathrm{o}}$ is reference density; Sis salinity; Tis temperature; $Q_{\mathrm{u}}$ and $Q_{\mathrm{v}}$ are the source and sink terms of momentum; $Q_{\mathrm{s}}$ is the source sink term of salinity; $Q_{T}$ is the source sink term of temperature. When other coefficients are known, the variable $u, v, w, p, \rho, S, T$ and $\zeta$ could be solved through simultaneous equations(1) to (8).

The relation between original vertical velocity $w^{*}$ and converted vertical velocity $w$ through $\sigma$ coordinate transformation is,

$$
w=w^{*}-z\left(\frac{\partial \zeta}{\partial}+u \frac{1}{m_{x}} \frac{\partial \zeta}{\partial x}+v \frac{1}{m_{y}} \frac{\partial \zeta}{\partial y}\right)+(1-z)\left(u \frac{1}{m_{x}} \frac{\partial h}{\partial x}+v \frac{1}{m_{y}} \frac{\partial h}{\partial y}\right)
$$

$H=h+\zeta$ is total depth of water, which is the sum of average depth $h$ and free water surface. Equation (5) is the continuity equation of equation (4) under integral depth, using the vertical boundary conditions $w=0$ where $z=0$ and $z=1$.

\section{B. Sediments TransportationModel}

The following equation is to describe the radioactive nuclide transferring and diffusing through sediments process.

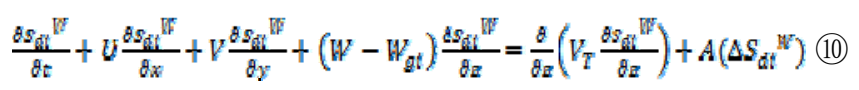

Where $S_{d i t}^{W}$ is concentration of isotopes i to $\mathrm{s}$ in water, $\mathrm{kg} / \mathrm{m}^{3} ; W_{S t}$ is the velocity of particle settled down, $\mathrm{m} / \mathrm{s} ; V_{T}$ is the vertical dispersion parameter and $\mathrm{A}$ is the horizontal dispersion parameter, $\mathrm{m}^{2} / \mathrm{s}$.

In the model, it neglects the effect of hydraulic dispersion to the suspension particles. The deposition velocity in horizontal direction is water velocity, the deposition of solid particle is considered in vertical plane. The nuclide concentration in bottom mud ridge, the thickness and porosity of bottom mud are expressed by corresponding equations.

\section{Nuclide Transportation Model}

The Chart provide the exchange processes of nuclides in water, suspension and sediment.

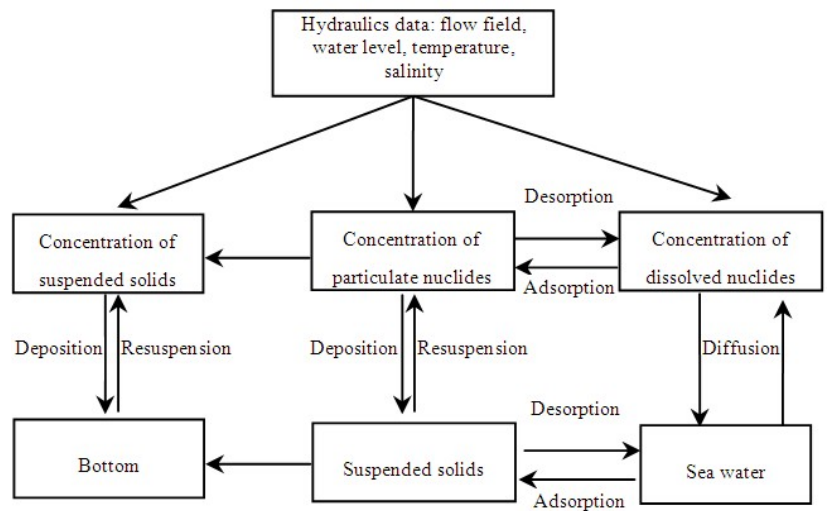

Fig. 1 Nuclide Transportation in Water, Suspension and Sediment

This model should include the concentration control equation to both dissolved and particle in water, and also include the concentration control equation to both sediments and particles in water. Theses equations can describe the exchange process of diffusion, absorption, sedimentation and resuspension. The transportation equation is:

$$
\begin{aligned}
& \frac{\partial C_{g} W}{\partial t}+U \frac{\partial C_{S}^{W}}{\partial x}+V \frac{\partial C_{g} W}{\partial y}+W \frac{\partial C_{g} W}{\partial z}=
\end{aligned}
$$

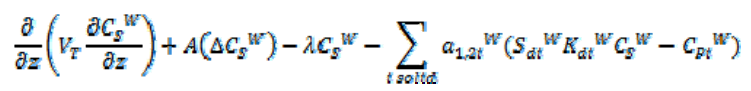

Where $S_{d i t}{ }^{W}$ is the nuclide concentration of i-s proportion in sediment; $\mathcal{C}_{P t}{ }^{W T}$ is the nuclide concentration of i-s proportionby adsorbed; $K_{d t}{ }^{W}$ is distribution coefficient between water and suspended solids of i-s proportion 。

\section{Perspective}

After Fukushima nuclear accident, researchers have paid increasingly attention to the radioactive material released to the fluid. However, it is urgent to build a comprehensive system to evaluation the radioactive dispersion in the water body and the impact to the ecology. For the further researches, the next step should focus on the definition of evaluation scale, 3D simulation, marine environment forecasting and radioactive isotopes transportation.

The proceeding work should concentrate on the next problems:

1. Clarify the scale that the simulation area, including coastal area , far from the shore area and mixed area.

2. Chose the mathematic models.

3. Coupling the system with the marine forecasting. 


\section{REFERENCES}

[1] International Atomic Energy Agency. International Fact Finding Expert Mission Of The Fukushima Dai-Ichi NPP Accident Following The Great East Japan Earthquake And Tsunami[R]. The Great East Japan Earthquake Expert Mission, Japan, 2011.

[2] WANG Shao-wei, WANG Hong-rui, CHEN Hai-ying, et al.Impact of Inland Nuclear Power Projects on Water Resource Safety and Corresponding Control Measures in China. China Rural Water and Hydropower, 2012, 6:43-46.

[3] Tokyo Electric Power Company. Release of the Fukushima Nuclear Accidents Investigation Report, http://www.tepco.co.jp/cc/press/betu12_j/images/120620j0303.pdf 2012.

[4] International Atomic Energy Agency. Generic Models for Use in Assessing the Impact of Discharges of Radioactive Substances to the Environment. IAEA, Vienna, 2001
[5] Karlsruhe Institute of Technology(KIT). The Real-time On-line Decision Support system for off-site emergency management in Europe(RODOS). http://www.rodos.fzk.de/rodos.html.

[6] Margvelashvily N, Maderich V, Zheleznyak M. Simulation of radionuclide fluxes from the Dnieper-Bug Estuary into the Black Sea. Journal of Environmental Radioactivity, 1999, 43(2):157-171.

[7] Margvelashvili N, Maderich V, Yusehenko S, Zheleznyak M. 3-D numerical modeling of mud and radionuclide transport in the Chernobyl Cooling pond and Dnieper-Boog Estuary. Proceedings in Marine Science, 2002, 5:595-609.

[8] Daisuke Tsumune, TakakiTsubono, Michio Aoyama, et.al. Distribution of oceanic 137Cs from the Fukushima Dai-ichi Nuclear Power Plant simulated numerically by a regional ocean model. Journal of Environmental

Radioactivity, 